\title{
Protective Effect of Curcuma Longa (Turmeric) on Serum Aspartate Aminotransferase and Lactate Dehydrogenase in Isoproterenol Induced Myocardial Injury in Rats
}

\author{
${ }^{*}$ Nahar $S^{1}$, Akhter $\mathrm{QS}^{2}$, Shumi MN³ , Tanvi $\mathrm{NEJ}^{4}$, Yeasmin $\mathrm{N}^{5}$, Akter $\mathrm{S}^{6}$, Yeasmin $S^{7}$
}

\begin{abstract}
Cardiovascular diseases (CVDs) emerging as a major health problem in Bangladesh due to increase prevalence of risk factors. Conventional cardioprotective drugs are effective but expensive and associated with a number of side effects. Curcuma longa is an important source of traditional medicine for the prevention and treatment of CVDs. The objective of the study was to evaluate the protective effect of Curcuma longa on isoproterenol induced myocardial injury in rats. This experimental study was carried out in the Department of Physiology, Dhaka Medical College, Dhaka during 2015. Total 21 Wistar albino male rats, aged 85 to 100 days, weighing 100 to $150 \mathrm{~g}$ (initial body weight) were selected for the study. After acclimatization for 14 days, the rats were divided into three groups. Group A (base line control group), Group B (isoproterenol treated control group) and Group $C$ (Curcuma longa pretreated and isoproterenol treated group). Each group consisted of 7 rats. On the $10^{\text {th }}$ day of experiment,
\end{abstract}

1. *Dr. Sharmin Nahar, Lecturer, Department of Physiology, Dhaka Medical College, Dhaka. Mobile: 01711576938 e-mail: sharmin. physiol16@gmail.com

2. Dr. Qazi Shamima Akhter, Professor \& Head, Department of Physiology, Dhaka Medical College, Dhaka.

3. Dr. Mahmuda Nasrin Shumi, Assistant Professor, Department of Physiology, Jahurul Islam Medical College, Bajitpur, Kishoregonj.

4. Dr. Noor-E-Jannat Tanvi, Lecturer, Department of Physiology, Shaheed Suhrawardy Medical College, Dhaka.

5. Dr. Nahid Yeasmin, Assistant Professor, Department of Physiology, Dhaka Medical College, Dhaka.

6. Dr. Shamima Akter, Assistant Professor, Department of Physiology, Dhaka Medical College, Dhaka.

7. Dr. Shahanara Yeasmin, Associate Professor, Department of Physiology, Dhaka Medical College, Dhaka.

*For correspondence rats were sacrificed after taking final body weight. Blood samples were collected from the heart. Serum aspartate aminotransferase (AST) level was estimated by Colorimetric method and lactate dehydrogenase (LDH) level was estimated by ELISA method. The statistical analysis was done by one way ANOVA and Bonferroni test as applicable. In this study, the mean initial and final body weight of the rats were almost similar and showed no statistically significant difference among the groups. The mean serum AST and LDH levels were significantly $(P<0.001)$ higher in Group $B$ than those of Group A. Again, these levels were significantly $(P<0.001)$ lower in Group $C$ than those of Group B group. From the results, it can be concluded that Curcuma longa has cardioprotective activity on isoproterenol induced myocardial injury in Wistar albino rats.

Keywords: Curcuma longa, Cardioprotective, Isoproterenol.

\section{INTRODUCTION}

Cardiovascular diseases (CVDs) remain as one of the leading causes of death though several advancements in the medical interventions. Among these, particularly the ischemic heart diseases and acute myocardial infarction (AMI) are most alarming. ${ }^{1}$ Due to increase prevalence of cardiovascular risk factors coronary heart disease increasing in rural population of Bangladesh. The major risk factors are hypertension, dislipidemia, diabetes mellitus, obesity, sedentary life style, old ages and cigarette smoking. ${ }^{2,3}$ In Bangladesh CVDs is an eminent medical and public health problem and is one of the major causes of death. ${ }^{4}$

Isoproterenol (ISP) is a sympathomimatic, $\beta$-adrenergic receptor agonist. ${ }^{5}$ It is used to produce myocardial injury in experimental animals for the evaluation of cardioprotective agents. ${ }^{6}$ High doses of isoproterenol injection destroy myocardial cells by increasing ionotropic effect of the heart that increases myocardial oxygen demand. It also causes severe oxidative stress in myocardium by generating free radicals and stimulates lipid peroxidation. As a result, cell membrane permeability increased and cytosolic enzymes are released into the bloodstream. Therefore, therapeutic interventions having antioxidants or free radical scavenging activity may be 
useful against oxidative stress associated with various cardiovascular diseases including myocardial infarction. ${ }^{7-9}$

Spices and herbs are renowned sources of natural antioxidants that can prevent oxidative stress. The therapeutic effects of folk plants are mainly recognized by the presence of flavonoids. ${ }^{10}$ In modern medicine, flavonoids are indicated as a potential treatment for CVDs due to its anti-inflammatory, antioxidant, and vasodilator effects. ${ }^{11}$

Herbal medicines are commonly used and considered as a convenient treatment because of their safety, efficacy and cost effectiveness as well as better compatibility. Plant derived medicines are comparatively safer than synthetic drugs. ${ }^{12}$ According to World Health Organization reports, about $80 \%$ peoples of developing countries preferred traditional medicine for their primary health care, and about $85 \%$ of such traditional medicine derived from plant extracts. ${ }^{13}$

Curcuma longa Linn. [Family: Zingiberaceae] is commonly known as turmeric. It is a rhizomatous perennial herb that is known as the "golden spice" as well as the "spice of life." It is widely used as a spice, food preservative and colouring material in India, China and South East Asia. Curcuma longa is widely cultivated in Bangladesh. So, it is cheap and easily available in our country. ${ }^{14}$ As a medicine, Curcuma longa has long been used to treat many health problems such as liver diseases, inflammation, digestive disorders and skin diseases. Curcuma longa possess several beneficial effects but no side effects have been reported till now. ${ }^{15}$ So it can be consumed as a dietary product all over the year.

Some investigators observed that body weight was significantly decreased and serum AST and LDH levels were significantly increased in rats treated with ISP (200mg/kg bw, subcutaneously) for 2 days. ${ }^{16}$ In cardiotoxic rats, the body weight might be decreased as a result of reduced intake of food. These are due to direct toxic effects on intestinal mucosa. ${ }^{17}$ During myocardial injury, AST and LDH released from the myocardial cells into the serum due to increased cell membrane permeability. ${ }^{18}$

Some other researchers suggested the cardioprotective effect of curcumin against doxorubicin induced myocardial toxicity in albino rats. Curcumin, a major active component of Curcuma longa significantly decreased serum AST and LDH levels. It maintains the normal structural and architectural integrity of myocardial cell by stabilizing the membrane. ${ }^{19}$ Therefore, on the basis of this background the present study was designed to evaluate the cardioprotective effect of Curcuma longa on isoproterenol induced myocardial injury in Wistar albino rats.

\section{MATERIALS AND METHODS}

This experimental study was conducted in the Department of Physiology, Dhaka Medical College, Dhaka from January to December, 2015. The protocol of this study was approved by Ethical Review Committee (ERC) of Dhaka Medical College. A total number of 21 Wistar albino male rats, aged 85 to 100 days, weighing 100 to $150 \mathrm{~g}$ were selected for the study. The animals were purchased from the animal house of Department of Pharmacy, Jahangirnagar University, Savar, Dhaka. The animals were kept in metallic case in the animal house of Institute of Nutrition and Food Science, University of Dhaka. Before conducting the study, they were kept in a standard laboratory condition on a 12/12 hour light/dark cycle for acclimatization. Total study period was 23 consecutive days. During this period all the rats had free access to food and water. After acclimatization for 14 days, the rats were divided into Group A (base line control group), Group B (isoproterenol treated control group) and Group C (Curcuma longa pretreated and isoproterenol treated group). Each group consisted of 7 rats. Initial body weight of all the rats was measured on $1^{\text {st }}$ day of experiment. All groups received basal diet for 9 consecutive days. In addition to basal diet, rats of Group A received normal saline orally $(1 \mathrm{ml} / \mathrm{kg}$ body weight) using intragastric tube for 9 consecutive days and Group B received isoproterenol subcutaneously $\left(150 \mathrm{mg} / \mathrm{kg}\right.$ body weight/day) on $8^{\text {th }}$ and $9^{\text {th }}$ day. Rats of Group $\mathrm{C}$ received ethanolic extract of Curcuma longa orally (200 mg/kg body weight) for 9 consecutive days and isoproterenol subcutaneously (150 $\mathrm{mg} / \mathrm{kg}$ body weight/day) on 8th and $9^{\text {th }}$ day. After taking final body weight, all the rats were anaesthetized by $30 \%$ chloroform and sacrificed on $10^{\text {th }}$ day. About $5 \mathrm{ml}$ of blood were collected from the heart of each rat. The blood was centrifuged and supernatant serum was collected and preserved in refrigerator for biochemical analysis. Serum aspartate aminotransferase (AST) level was estimated by Colorimetric method ${ }^{20}$ and lactate dehydrogenase (LDH) level was estimated by ELISA method. ${ }^{21}$ Data were expressed as mean $( \pm S D)$. The results were compared among different groups. The statistical analysis was done by one way ANOVA and Bonferroni test as applicable. P value $<0.05$ was considered as significant. 


\section{RESULTS}

The mean $( \pm \mathrm{SD})$ initial (I) body weights were 127.14 $\pm 14.96,127.14 \pm 11.12$ and $115.71 \pm 13.97 \mathrm{gm}$ on day-1 whereas the final (F) body weight were $122.85 \pm 11.12, \quad 112.85 \pm 11.12$ and $111.71 \pm 10.67$ on day-10 in group A, B and C respectively. The mean $( \pm S D)$ initial (I) and final (F) body weight of the rats were almost similar and showed no statistically significant difference among the groups (Figure 1).

In this study, serum AST and LDH levels were significantly higher $(\mathrm{P}<0.001)$ in Group B in comparison to those of Group A. Again, these levels were significantly lower in Group C than those of Group B. Moreover, LDH $(\mathrm{P}<0.001)$ level was significantly higher in Group $\mathrm{C}$ than that of Group A but there were no significant difference between AST level of Group A and Group C (Table I).

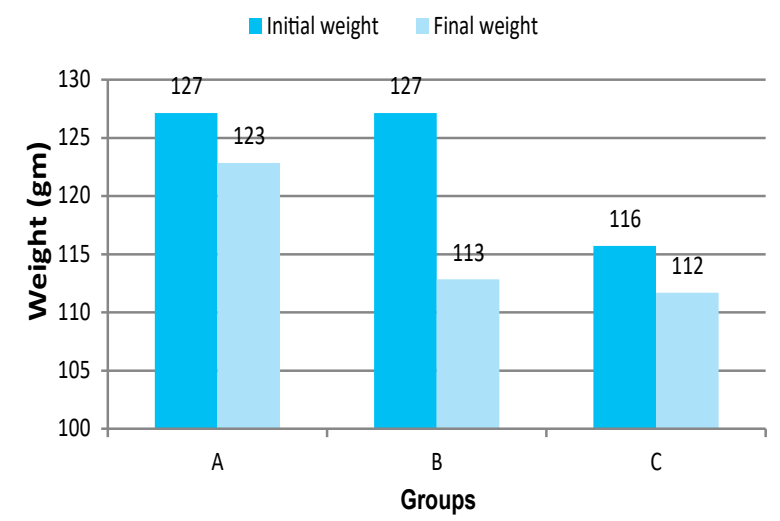

Figure 1: Mean initial and final body weight in different groups of rats $(\mathrm{N}=21)$

$\mathrm{N}=$ Number of rats A: Baseline control group

B: Isoproterenol treated control group

C: Curcuma longa pretreated \& isoproterenol treated group

Table I: Serum AST and LDH levels in different groups of rats $(\mathrm{N}=21)$

\begin{tabular}{|l|c|c|c|}
\hline $\begin{array}{c}\text { Parameter } \\
(\mathrm{U} / \mathrm{L})\end{array}$ & $\mathrm{A}$ & Groups & \\
\cline { 2 - 4 } & $(\mathrm{n}=7)$ & $\begin{array}{c}\mathrm{B} \\
(\mathrm{n}=7)\end{array}$ & $\begin{array}{c}\mathrm{C} \\
(\mathrm{n}=7)\end{array}$ \\
\hline AST & $35.70 \pm 2.71$ & $614.92 \pm 73.39^{* * *}$ & $41.38 \pm 2.76^{\# \#}$ \\
\hline LDH & $206.7 \pm 73.61^{\wedge \wedge \wedge}$ & $731.59 \pm 124.41^{* * *}$ & $452.55 \pm 70.75^{\# \#}$ \\
\hline
\end{tabular}

Values are means \pm SD. Statistical analysis was done by one way ANOVA and then Bonferroni test. $\mathrm{N}=$ Number of rats. For serum AST \& LDH, $\left({ }^{* * *} \mathrm{p}<0.001 \mathrm{~A}\right.$ vs $\left.\mathrm{B}\right),\left({ }^{\# \#} \mathrm{P}<0.001 \mathrm{~B}\right.$ vs $\left.\mathrm{C}\right)$. For serum $\mathrm{LDH}\left({ }^{\wedge \wedge \wedge} \mathrm{p}<0.001 \mathrm{~A}\right.$ vs $\left.\mathrm{C}\right) \mathrm{A}=$ Baseline control group, $\mathrm{B}=$ Isoproterenol treated control group $\mathrm{C}=$ Curcuma longa pretreated and Isoproterenol treated group.

\section{DISCUSSION}

In the present study, the final body weight of all the rats were decreased than their initial body weight, but no significant difference were observed. Similar type of observation was found by some other research worker. ${ }^{22}$ But some investigators observed that body weight was significantly decreased in experimental myocardial injury. In that study the researcher used isoproterenol $(300 \mathrm{mg} / \mathrm{kg}$ bw, subcutaneously) to induce myocardial injury. ${ }^{23}$

In this study, mean serum AST and LDH levels were significantly higher $(\mathrm{P}<0.001)$ in isoproterenol treated control group in comparison to those of baseline control group. Again, these levels were significantly lower $(\mathrm{P}<0.001)$ in Curcuma longa pretreated and isoproterenol treated group than those of isoproterenol treated control group. Similar findings were also reported by different investigators but they used curcumin as an alternative of Curcuma longa. ${ }^{19,24}$ Mean serum LDH level was significantly higher $(\mathrm{P}<0.001)$ in Curcuma longa pretreated and isoproterenol treated group than that of baseline control group. But mean serum AST level was non significantly higher among those groups. However, almost similar type of published data was not observed to compare these findings.

Some researcher observed that subcutaneous injection of ISP in experimental animals causes severe oxidative stress in myocardium resulting infarct like lesion in the heart muscles. ${ }^{9}$ It generates free radicals and stimulates lipid peroxidation that causes irreversible damage to the myocardial membrane in experimental myocardial infarction. ${ }^{8}$ Thus serum aspartate aminotransferase (AST) and lactate dehydrogenase $(\mathrm{LDH})$ enzymes were significantly increased due to cell necrosis. ${ }^{25,26}$ But pretreatment with Curcuma longa protects myocardium against isoproterenol induced myocardial injury which is evidenced by improved histopathological findings of myocardium. ${ }^{27}$

In the present study, isoproterenol induced myocardial injury in rats was evidenced by reduced body weight, higher level of serum AST and LDH levels. These changes may be due to increased production of free radicals which initiate lipid peroxidation and subsequent myocardial cell damage. Again, increased body weight, lower level of serum AST and LDH in Curcuma longa pretreated and isoproterenol treated rats suggested that Curcuma longa is responsible for cardioprotection. This effect is possibly due to antioxidant and free radical scavenging activity of Curcuma longa. 


\section{CONCLUSIONS}

The result of the present study reveals that the Curcuma longa has cadioprotective effect on isoproterenol induced myocardial injury in rats. So, it is acceptable as a daily source of natural antioxidant and an herbal medicine for the prevention of cardiovascular disease.

\section{Acknowledgement}

The authors of this study gratefully acknowledge Professor Dr. Sheikh Nazrul Islam, Institute of Nutrition and Food Science, University of Dhaka, for the cooperation regarding laboratory facilities he provided.

\section{References}

1. Upaganlawar A, Gandhi H, Balaraman R. Isoproterenol induced myocardial infarction: protective role of natural products. J Pharmacol Toxicol 2011; 6(1): 1-17.

2. Sayeed MA, Mahtab H, Sayeed S, Begum T, Khanam PA, Banu A. Prevalence and risk factors of coronary heart disease in a rural population of Bangladesh. Ibrahim Med. Coll. J. 2010; 4(2): 37-43.

3. Saradha A, Jhan TMG. Cardiovascular disease treatment strategies. Health Action 2009; 22: 28-31.

4. Islam MAKM, Majumder AAS. Coronary artery disease in Bangladesh: A review. Indian Heart J 2013; 65: 424-35.

5. Hoffman BB. Adrenoceptor antagonist drugs in Katzung BG. Basic and Clinical Pharmacology. 8th ed. The McGraw Hill Copaniesz: America 2001; p.138-52.

6. Devika PT, Prince PSM. Protective effect of (-)-epigallocatechin-gallate (EGCG) on lipid peroxide metabolism in isoproterenol induced myocardial infarction in male Wistar rats: a histopathological study. Biomed Pharmacother 2008; 62(10):701- 8 .

7. Trivedi CJ, Balaraman R, Majithiya JB, Bothara SB. Effect of atorvastatin treatment on isoproterenol induced myocardial infarction in rats. Pharmacol 2006; 77: 25-32.

8. Senthilkumar H, Anandan R, Devaki T, Santhoshkumar M. Cardioprotective effects of Picrorrhiza kurrora against isoproterenol induced myocardial stress in rats. Fitoterapia 2001; 72: 402- 5.

9. Patel V, Upaganlawar A, Zalawadia R, Balaraman R. Cardioprotective effect of melatonin against isoproterenol induced myocardial infarction in rats: $\mathrm{A}$ biochemical, electrocardiographic and histoarchitectural evaluation. Eur J Pharmacol 2010; 644:160-8.

10. Repetto MG, Llesuy SF. Antioxidant properties of natural compounds used in popular medicine for gastric ulcers. Braz. J. Med. Biol. Res. 2002; 35(35):523-34.

11. Samarghandian S, Azimini-Nezhad M, Farkhondeh T. The effects of Zataria multiflora on blood glucose, lipid profile and oxidative stress parameters in adult mice during exposure to bisphenol A. Cardiovasc Hematol Disord Dmg Targets 2016; 16(1): 41-6.

12. Ripunjoy $S$. Indigenous knowledge in the utilization of medecinal plants by the Sonowal Keracho tribe of Dibrugarh district in Assam, north-east India. Int Res J Biol Sci 2013; 2(4): 44-50.

13. World Health Organization. Research Guidelines for Evaluating the Safety and Efficacy of Herbal Medicines. Manila 1993; 1-94.

14. Shrishail S, Harish HK, Ravichandra H, Shruthi SD. Turmeric: Nature's precious medicine. Asian J Pharm clin Res 2013; 6 (3): 10-6.

15. Karim MR, Haque A, Islam K, Ali N, Salam KA, Saud ZA, Hossain E, Fajol A, Akhand AA, Himeno S, Hossain K. Protective effects of the dietary supplementation of turmeric (Curcuma longa L.) on sodium arsenite-induced biochemical perturbation in mice. Bangladesh Med Res Counc Bull 2010; 36: 82-8.

16. Upaganlawar A, Gandhi H, Balaraman R. Effect of vitamin $\mathrm{E}$ alone and in combination with lycopene on biochemical and histopathological alterations in isoproterenol induced myocardial infarction in rats. J of Pharmacol and pharmacotheraputics 2010; 1(1): 24-31.

17. Herman EH, Zhang J, Chadwick DP, Ferrans V. Comparison of the protective effect of amifostine and dexrazoxane against toxicity of doxorubicin in spontaneously hypertensive rats. Cancer Chemother. Pharmacol. 2000; 45: 329-34.

18. Arya DS, Bansal P, Ojha SK, Nandav M, Mohanty I, Gupta SK. Pyruvate provides cardioprotection in the experimental model of myocardial ischemic reperfusion injury. Life sci 2006; 79: 38-44.

19. Swamy AV, Gulliaya S, Thippeswamy A, Koti BC, Manjula DV. Cardioprotective effect of curcumin against doxorubicin induced myocardial toxicity in albino rats. Indian J Pharm 2012; 44(1): 73-7. 
20. Reitman S, Frankel S. Glutamic pyruvic and oxaloacetic transaminase. Amer J Clin Path. 1957; 28: 56.

21. IFCC. Primary reference procedure for the measurement of catalytic activity concentrations of enzymes at 37。C.Part 3: Reference procedure for the measurement of catalytic activity concentrations of lactate dehydrogenase. Clin Chem Lab Med.2002; 40: 643-48.

22. Khalil MI, Ahmmed I, Ahmed R, Tanvir EM, Afroz R, Paul S, Gan SH, Alam N. Amelioration of isoproterenol-induced oxidative damage in rat myocardium by Withania somnifera leaf extract. BioMed Research International 2015; 2015 (Article ID 624159):1-10.

23. Nirmala C, Puvanakrishnan R. Effect of curcumin on certain lysosomal hydrolases in isoproterenol-induced myocardial infarction in rats. Biochem Pharmacol 1996; 51: 47-51.
24. Ansari MN, Bhandari U, Pillai KK. Protective role of curcumin in myocardial oxidative damage induced by isoproterenol in rats. Hum Exp Toxicol 2007; 26(12): 933-38.

25. Filho HGL, Ferreira LN, Sousa RB, Carvalho ER, Lobo PLD, Filho JGL. Experimental model of myocardial infarction induced by isoproterenol in rats. Rev Bras Cir Cardiovasc 2011; 26(3): 469-76.

26. Sasikumar SC, Devi SCS. Protective effect of Abana. A polyherbal formulation on isoproterenol induced myocardial infarction in rats. Indian J Pharmacol 2000; 32:198- 201.

27. Mohanty IR, Arya DS, Gupta SK. Dietary Curcuma longa protects myocardium against isoproterenol induced hemodynamic, biochemical and histopathological alterations in rats. Int J Appl Res Nat Prod. 2009; 1(4):19-28. 